\section{META-ANALYSIS ON THE INCIDENCE OF HYPERPROGRESSIVE DISEASE DURING IMMUNE CHECKPOINT INHIBITOR THERAPY}

${ }^{1}$ Seung Pyo Hong*, 'Min Jeong Kim, ${ }^{2}$ Allison Belette, ${ }^{1}$ Youjin Oh, ${ }^{3}$ Sukjoo Cho, ${ }^{1}$ Young Kwang Chae. 'Northwestern University Feinberg School of Medicine, Chicago, IL, USA; ${ }^{2}$ University of Texas, Houston, TX, USA; ${ }^{3}$ University of South Florida Morsani College of Medicine, Tampa, FL, USA

Background Hyperprogressive disease (HPD) is a distinct pattern of rapid tumor progression observed in patients with cancer who are undergoing immune checkpoint inhibitor therapy. Despite the growing evidence, a universal definition of HPD remains to be established, and incidence rates vary based on the defining criteria. Therefore, a refinement of currently existing criteria is warranted to better characterize this phenomenon and evaluate its incidence.

Methods Two independent investigators performed a systematic literature search in EMBASE and MEDLINE using keywords selected in Park et al. ${ }^{1}$ : checkpoint, immunotherapy, pd1, pdl1, ctla4, ipilimumab, nivolumab, pembrolizumab, atezolizumab, avelumab, durvalumab and hyperprogress. Studies published from March 3, 2020 to April 20, 2020 that included the incidence and definition of HPD in patients receiving immunotherapy were included for analysis. Selected studies were then combined with those included in the meta-analysis by Park et al. ${ }^{1}$ Duplicates were removed, and the study with a larger cohort was selected in instances of overlap between two cohorts. In total, 50 studies were included for meta-analysis. $^{2-51}$ Pooled incidence rates of HPD and prespecified subgroup analyses based on four categories defining HPD (tumor growth rate ratio, tumor growth kinetics ratio, early tumor burden increase, and combination) were obtained with 95\% confidence intervals (CI) using a random effects model performed on R.

Results A total of 6009 patients from 50 studies were included in the meta-analysis. Incidences varied from $0.0 \%$ to $43.1 \%$ (figure 1), and the overall pooled incidence of HPD was $12.9 \%$ (95\%CI, 11.1\%-14.7\%). Significant heterogeneity was observed $(\mathrm{I} 2=77 \% ; \mathrm{p}<0.01)$. Studies were also grouped into one of 4 categories (table 1) based on the definition of HPD used to calculate the tumor growth acceleration: tumor growth rate ratio (pooled incidence of HPD 10.5\%; 95\% CI, 7.9\%-13.0\%), tumor growth kinetics ratio (pooled incidence, $14.8 \%$; 95\% CI, $12.0 \%-17.5 \%)$, early tumor burden increase (pooled incidence, 17.2\%; 95\% CI, 9.7\%-24.7\%), and combinations of the above (pooled incidence, 12.2\%; 95\% CI, $9.2 \%-15.2 \%)$.

Abstract 238 Table 1 Subgroup analyses based on definitions of HPD

\begin{tabular}{|c|c|c|c|c|c|}
\hline \multirow{2}{*}{$\begin{array}{l}\text { Factor } \\
\text { HPD definition }\end{array}$} & \multirow{2}{*}{$\begin{array}{c}\text { Pooled } \\
\text { incidence of } \\
\text { HPD (\%) }\end{array}$} & \multicolumn{4}{|c|}{$P$ value } \\
\hline & & $\begin{array}{c}\text { vs Category } \\
1\end{array}$ & \begin{tabular}{|c|} 
vs Category \\
2
\end{tabular} & $\begin{array}{c}\text { vs Category } \\
3\end{array}$ & $\begin{array}{c}\text { vs Category } \\
4\end{array}$ \\
\hline Category 1 (TGR ratio) & $\begin{array}{c}10.5 \\
(7.9-13.0)\end{array}$ & - & 0.025 & 0.097 & 0.385 \\
\hline Category 2 (TGK ratio) & $\begin{array}{c}14.8 \\
(12.0-17.5)\end{array}$ & 0.025 & - & 0.552 & 0.223 \\
\hline Category 3 (early tumor burden increase) & $\begin{array}{c}17.2 \\
(9.7-24.7)\end{array}$ & 0.097 & 0.552 & - & 0.229 \\
\hline Category 4 (combination) & $\begin{array}{c}12.2 \\
(9.2-15.2)\end{array}$ & 0.385 & 0.223 & 0.229 & - \\
\hline
\end{tabular}

Abbreviation: TGR, tumor growth rate; TGK, tumor growth kinetics.

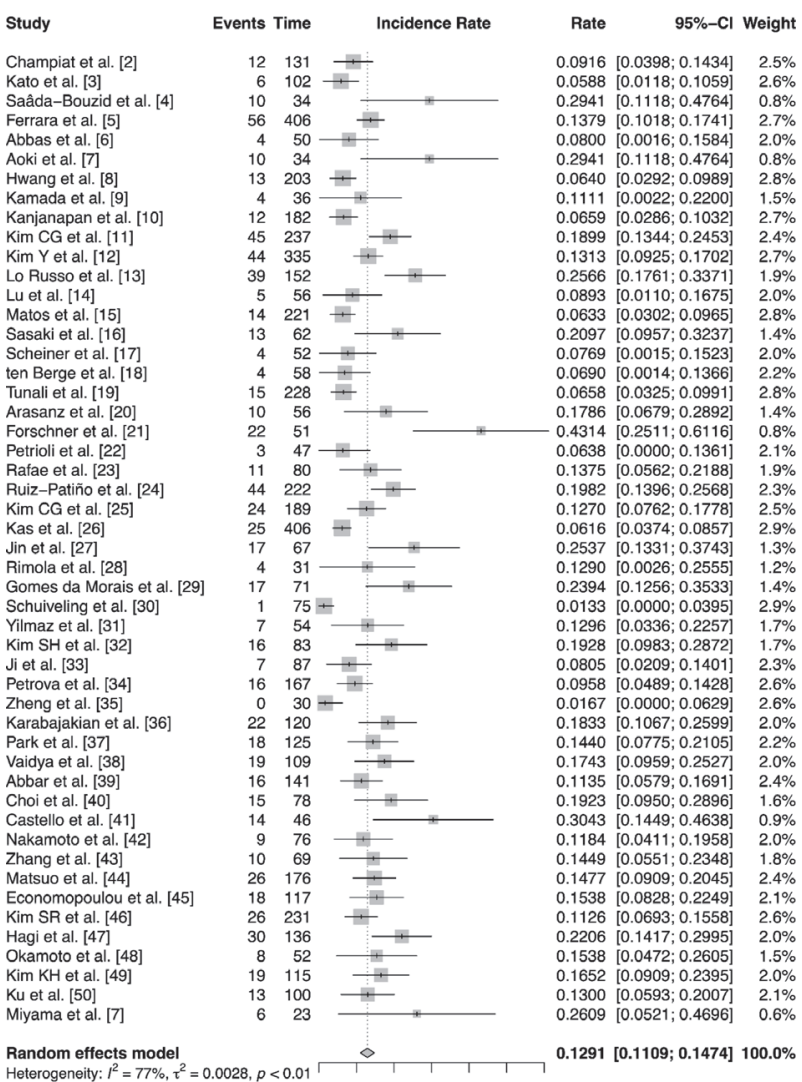

Abstact 238 Figure 1 Overall pooled incidence of HPD. The overall pooled incidence of HPD was $12.9 \%(95 \% \mathrm{Cl}, 11.1 \%-14.7 \%)$.

Significant heterogeneity was observed $(12=77 \% ; \mathrm{p}<0.01)$.

Conclusions The overall incidence of HPD from 50 studies was $12.9 \%$ (95\%CI, 11.1\%-14.7\%). HPD incidence varied from $0 \%$ to $43.1 \%$ depending on the definition each investigator chose. There is a growing need for a more uniform definition of HPD that does not underestimate or overestimate its incidence.

\section{REFERENCES}

1.. Park HJ, Kim KW, Won SE, et al. Definition, incidence, and challenges for assessment of hyperprogressive disease during cancer treatment with immune checkpoint inhibitors: a systematic review and meta-analysis. JAMA Netw Open 2021;4 (3):1-16. doi:10.1001/jamanetworkopen.2021.1136

2.. Champiat S, Dercle L, Ammari S, et al. Hyperprogressive disease is a new pattern of progression in cancer patients treated by anti-PD-1/PD-L1. Clin Cancer Res 2017;23(8):1920-1928. doi:10.1158/1078-0432.CCR-16-1741

3. Kato S, Goodman A, Walavalkar V, Barkauskas DA, Sharabi A, Kurzrock R. Hyperprogressors after immunotherapy: analysis of genomic alterations associated with accelerated growth rate. Clin Cancer Res 2017;23(15):4242-4250. doi:10.1158/ 1078-0432.CCR-16-3133

4.. Saâda-Bouzid E, Defaucheux C, Karabajakian A, et al. Hyperprogression during anti-PD-1/PD-L1 therapy in patients with recurrent and/or metastatic head and neck squamous cell carcinoma. Ann Oncol 2017;28(7):1605-1611. doi:10.1093/ annonc/mdx178

5.. Ferrara R, Mezquita L, Texier M, et al. Comparison of fast-progression, hyperprogressive disease, and early deaths in advanced non-small-cell lung cancer treated with PD-1/PD-L1 inhibitors or chemotherapy. JCO Precis Oncol 2020;(4):829-840. doi:10.1200/po.20.00021

6.. Abbas W, Rao RR, Popli S. Hyperprogression after immunotherapy. South Asian J Cancer 2019;08(04):244-246. doi:10.4103/sajc.sajc_389_18

7.. Aoki M, Shoji H, Nagashima K, et al. Hyperprogressive disease during nivolumab or irinotecan treatment in patients with advanced gastric cancer. ESMO Open 2019;4(3):1-10. doi:10.1136/esmoopen-2019-000488 
8.. Hwang I, Park I, Yoon S kyo, Lee JL. Hyperprogressive disease in patients with urothelial carcinoma or renal cell carcinoma treated with PD-1/PD-L1 inhibitors. Clin Genitourin Cancer 2020;18(2):e122-e133. doi:10.1016/j.clgc.2019.09.009

9.. Kamada T, Togashi Y, Tay C, et al. PD-1+ regulatory T cells amplified by PD-1 blockade promote hyperprogression of cancer. Proc Natl Acad Sci U S A 2019;116(20):9999-10008. doi:10.1073/pnas. 1822001116

10.. Kanjanapan Y, Day D, Wang $L$, et al. Hyperprogressive disease in early-phase immunotherapy trials: clinical predictors and association with immune-related toxicities. Cancer 2019;125(8):1341-1349. doi:10.1002/cncr.31999

11.. Kim CG, Kim KH, Pyo KH, et al. Hyperprogressive disease during PD-1/PD-L1 blockade in patients with non-small-cell lung cancer. Ann Oncol 2019;30 (7):1104-1113. doi:10.1093/annonc/mdz123

12.. Kim Y, Kim CH, Lee HY, et al. Comprehensive clinical and genetic characterization of hyperprogression based on volumetry in advanced non-small cell lung cancer treated with immune checkpoint inhibitor. I Thorac Oncol 2019;14(9):16081618. doi:10.1016/j.jtho.2019.05.033

13.. Russo G Lo, Moro M, Sommariva $M$, et al. Antibody-Fc/FcR interaction on macrophages as a mechanism for hyperprogressive disease in non-small cell lung cancer subsequent to PD-1/PD-L1 blockade. Clin Cancer Res 2019;25(3):989-999. doi:10.1158/1078-0432.CCR-18-1390

14.. Lu Z, Zou J, Hu Y, et al. Serological markers associated with response to immune checkpoint blockade in metastatic gastrointestinal tract cancer. JAMA Netw Open 2019;2(7):1-15. doi:10.1001/jamanetworkopen.2019.7621

15.. Matos

I, Martin-Liberal J, García-Ruiz A, et al. Capturing hyperprogressive disease with immune-checkpoint inhibitors using RECIST 1.1 criteria. Clin Cancer Res 2020;26 (8):1846-1855. doi:10.1158/1078-0432.CCR-19-2226

16.. Sasaki A, Nakamura Y, Mishima $S$, et al. Predictive factors for hyperprogressive disease during nivolumab as anti-PD1 treatment in patients with advanced gastric cancer. Gastric Cancer 2019;22(4):793-802. doi:10.1007/s10120-018-00922-8

17.. Scheiner B, Kirstein MM, Hucke F, et al. Programmed cell death protein-1 (PD-1)targeted immunotherapy in advanced hepatocellular carcinoma: efficacy and safety data from an international multicentre real-world cohort. Aliment Pharmacol Ther 2019:49(10):1323-1333. doi:10.1111/apt.15245

Ten Berge DMHJ, Hurkmans DP, den Besten I, et al. Tumour growth rate as a tool for response evaluation during PD- 1 treatment for non-small cell lung cancer: a retrospective analysis. ERJ Open Res 2019;5(4):00179-02019. doi:10.1183/23120541.001792019

19.. Tunali I, Gray JE, Qi J, et al. Novel clinical and radiomic predictors of rapid disease progression phenotypes among lung cancer patients treated with immunotherapy: an early report. Lung Cancer 2019;129:75-79. doi:10.1016/j. lungcan.2019.01.010

20.. Arasanz H, Zuazo M, Bocanegra A, et al. Early detection of hyperprogressive disease in non-small cell lung cancer by monitoring of systemic T cell dynamics. Cancers (Basel) 2020;12(2):1-14. doi:10.3390/cancers12020344

21.. Forschner A, Hilke FJ, Bonzheim I, et al. MDM2, MDM4 and EGFR amplifications and hyperprogression in metastatic acral and mucosal melanoma. Cancers (Basel) 2020;12(3). doi:10.3390/cancers12030540

22.. Petrioli R, Mazzei MA, Giorgi $S$, et al. Hyperprogressive disease in advanced cancer patients treated with nivolumab: a case series study. Anticancer Drugs. Published online 2020:190-195. doi:10.1097/CAD.0000000000000864

Refae S, Gal J, Brest $\mathrm{P}$, et al. Author correction: hyperprogression under immune checkpoint inhibitor: a potential role for germinal immunogenetics (Scientific Reports, (2020), 10, 1，(3565), 10.1038/s41598-020-60437-0). Sci Rep 2020;10(1):1-8. doi:10.1038/s41598-020-66841-w

24.. Ruiz-Patiño A, Arrieta O, Cardona AF, et al. Immunotherapy at any line of treatment improves survival in patients with advanced metastatic non-small cell lung cancer (NSCLC) compared with chemotherapy (Quijote-CLICaP). Thorac Cancer 2020;11(2):353-361. doi:10.1111/1759-7714.13272

25. Kim CG, Kim C, Yoon SE, et al. Hyperprogressive disease during PD-1 blockade in patients with advanced hepatocellular carcinoma. J Hepatol 2021;74(2):350359. doi:10.1016/i.jhep.2020.08.010

26.. Kas

$B$, Talbot $H$, Ferrara $R$, et al. Clarification of definitions of hyperprogressive disease during immunotherapy for non-small cell lung cancer. JAMA Oncol 2020;6 (7):1039-1046. doi:10.1001/jamaoncol.2020.1634

27.. Jin T, Zhang Q, Jin QF, Hua YH, Chen XZ. Anti-PD1 checkpoint inhibitor with or without chemotherapy for patients with recurrent and metastatic nasopharyngeal carcinoma. Trans/ Oncol 2021;14(2):100989. doi:10.1016/j.tranon.2020.100989

28.. Rimola J, Da Fonseca LG, Sapena V, et al. Radiological response to nivolumab in patients with hepatocellular carcinoma: a multicenter analysis of real-life practice. Eur J Radiol 2021:135(December 2020). doi:10.1016/..ejrad.2020.109484

29.. Gomes da Morais AL, de Miguel M, Cardenas JM, Calvo E. Comparison of radiological criteria for hyperprogressive disease in response to immunotherapy. Cancer Treat Rev 2020;91(September). doi:10.1016/j.ctrv.2020.102116
30.. Schuiveling M, Tonk EHJ, Verheijden RJ, Suijkerbuijk KPM. Hyperprogressive disease rarely occurs during checkpoint inhibitor treatment for advanced melanoma. Cancer Immunol Immunother 2021;70:1491-1496. doi:10.1007/s00262-020 02716-3

31. 31. Yilmaz M. Atypical response patterns in metastatic melanoma and renal cell carcinoma patients treated with nivolumab: a single center experience. I Oncol Pharm Pract 2021:27(5):1106-1111. doi:10.1177/1078155220949642

32.. Kim SH, Choi CM, Lee DH, et al. Clinical outcomes of nivolumab in patients with advanced non-small cell lung cancer in real-world practice, with an emphasis on hyper-progressive disease. J Cancer Res Clin Oncol 2020;146(11):3025-3036. doi:10.1007/s00432-020-03293-9

33.. Ji Z, Cui Y, Peng Z, et al. Use of radiomics to predict response to immunotherapy of malignant tumors of the digestive system. Med Sci Monit 2020;26:1-9. doi:10.12659/MSM.92467

34.. Petrova MP, Donev IS, Radanova MA, et al. Sarcopenia and high NLR are associated with the development of hyperprogressive disease after second-line pembrolizumab in patients with non-small-cell lung cancer. Clin Exp Immunol 2020;202 (3):353-362. doi:10.1111/cei.13505

35.. Zheng B, Shin JH, Li H, Chen Y, Guo Y, Wang M. Comparison of radiologica tumor response based on RRECIST and RECIST 1.1 in metastatic clear-cell renal cell carcinoma patients treated with programmed cell death-1 inhibitor therapy. Korean J Radiol 2021;22(3):366-375. doi:10.3348/kj.2020.0404

36.. Karabajakian A, Garrivier T, Crozes C, et al. Hyperprogression and impact of tumor growth kinetics after PD1/PDL1 inhibition in head and neck squamous cell carcinoma. Oncotarget 2020;11(18):1618-1628. doi:10.18632/oncotarget.27563

37.. Park JH, Chun SH, Lee YG, et al. Hyperprogressive disease and its clinical impact in patients with recurrent and/or metastatic head and neck squamous cell carcinoma treated with immune-checkpoint inhibitors: Korean cancer study group HN 18-12. J Cancer Res Clin Oncol 2020;(0123456789). doi:10.1007/s00432-02003316-5

38.. Vaidya $P$, Bera $K$, Patil PD, et al. Novel, non-invasive imaging approach to identify patients with advanced non-small cell lung cancer at risk of hyperprogressive disease with immune checkpoint blockade. J Immunother Cancer 2020;8(2) doi:10.1136/jitc-2020-001343

39.. Abbar B, De Castelbajac V, Gougis P, et al. Definitions, outcomes, and management of hyperprogression in patients with non-small-cell lung cancer treated with immune checkpoint inhibitors. Lung Cancer 2021;152(December 2020):109-118. doi:10.1016/j.lungcan.2020.12.026

40.. Choi YJ, Kim T, Kim EY, Lee SH, Kwon DS, Chang YS. Prediction model for hyperprogressive disease in non-small cell lung cancer treated with immune checkpoint inhibitors. Thorac Cancer 2020:11(10):2793-2803. doi:10.1111/17597714.13594

41.. Castello A, Rossi S, Mazziotti E, Toschi L, Lopci E. Hyperprogressive disease in patients with non-small cell lung cancer treated with checkpoint inhibitors: the role of 18F-FDG PET/CT. J Nucl Med 2020:61(6):821-826. doi:10.2967/ jnumed. 119.237768

42.. Nakamoto R, C Zaba L, Rosenberg J, et al. Imaging characteristics and diagnostic performance of 2-deoxy-2-[18F]fluoro-d-Glucose PET/CT for melanoma patients who demonstrate hyperprogressive disease when treated with immunotherapy. Mol Imaging Biol 2021:23(1):139-147. doi:10.1007/s11307-020-01526-4

43.. Zhang L, Wu L, Chen Q, et al. Predicting hyperprogressive disease in patients with advanced hepatocellular carcinoma treated with anti-programmed cell death 1 therapy. EClinicalMedicine 2021:31:100673. doi:10.1016/j.eclinm.2020.100673

44.. Matsuo N, Azuma K, Kojima T, et al. Comparative incidence of immune-related adverse events and hyperprogressive disease in patients with non-small cell lung cancer receiving immune checkpoint inhibitors with and without chemotherapy. Invest New Drugs Published online 2021. doi:10.1007/s10637-021-01069-7

45.. Economopoulou P, Anastasiou M, Papaxoinis $G$, et al. Patterns of response to immune checkpoint inhibitors in association with genomic and clinical features in patients with head and neck squamous cell carcinoma (HNSCC). Cancers (Basel) 2021;13(2):1-15. doi:10.3390/cancers13020286

46.. Kim SR, Chun SH, Kim JR, et al. The implications of clinical risk factors, CAR index, and compositional changes of immune cells on hyperprogressive disease in non-small cell lung cancer patients receiving immunotherapy. BMC Cancer 2021;21(1):1-11. doi:10.1186/s12885-020-07727-y

47.. Hagi T, Kurokawa $Y$, Kawabata $R$, et al. Multicentre biomarker cohort study on the efficacy of nivolumab treatment for gastric cancer. Br J Cancer 2020;123 (6):965-972. doi:10.1038/s41416-020-0975-7

48.. Okamoto I, Sato H, Tsukahara K. Overall survival and PD-L1 expression in patients with recurrent or metastatic head and neck cancer treated with nivolumab. Auris Nasus Larynx 2020;47(4):676-686. doi:10.1016/j.anl.2020.04.001

49.. Kim KH, Hur JY, Koh J, et al. Immunological characteristics of hyperprogressive disease in patients with non-small cell lung cancer treated with anti-pd-1/pd-11 abs. Immune Netw 2020:20(6):1-11. doi:10.4110/in.2020.20.e48

50.. Ku BM, Kim Y, Lee KY, et al. Tumor infiltrated immune cell types support distinct immune checkpoint inhibitor outcomes in patients with advanced non-small cell 


\section{Abstracts}

lung cancer. Eur J Immunol Published online 2021:1-9. doi:10.1002/ eji.202048966

51.. Miyama Y, Morikawa T, Miyakawa J, et al. Squamous differentiation is a potential biomarker predicting tumor progression in patients treated with pembrolizumab for urothelial carcinoma. Pathol Res Pract 2021;219(February):153364. doi:10.1016/j.prp.2021.153364

http://dx.doi.org/10.1136/jitc-2021-SITC2021.238 